\title{
|!:
}

\section{APLICAÇÃO DO CICLO PDCA INTEGRADO AO PLANO DE QUALIFICAÇÃO DE FORNECEDORES DE LEITE}

\author{
APPLICATION OF THE PDCA CYCLE INTEGRATED TO THE QUALIFICATION PLAN \\ FOR MILK SUPPLIERS
}

\author{
${ }^{1}$ Patrick Pereira dos Santos \\ ${ }^{2 *}$ Gabriel Domingos Carvalho \\ ${ }^{3}$ Clayton Perônico de Almeida \\ ${ }^{4}$ Dayse Aline Ferreira Silva Bartolomeu
}

\begin{abstract}
${ }^{1}$ Instituto Federal do Espírito Santo - Ifes Campus Piúma. E-mail: patrick.pds2@ gmail.com ${ }^{2}$ Instituto Federal do Espírito Santo - Ifes Campus Piúma. E-mail: gabriel.carvalho@ifes.edu.br

${ }^{3}$ Instituto Federal do Espírito Santo - Ifes Campus Piúma. E-mail: cperonico@ifes.edu.br

${ }^{4}$ Instituto Federal do Espírito Santo - Ifes Campus Piúma. E-mail: dbartolomeu@ifes.edu.br

*Autor de correspondência
\end{abstract}

Artigo submetido em 11/02/2021, aceito em 03/08/2021 e publicado em 23/08/2021.

Resumo: O leite é um alimento bastante completo, fonte de proteínas, lipídeos, vitaminas e minerais. Para a obtenção de produtos lácteos de boa qualidade, que contribuam com a saúde e bem-estar dos consumidores, precisa-se de uma matéria-prima de boa qualidade. Para isso, as fazendas leiteiras precisam melhorar a gestão agropecuária através do investimento em genética, nutrição, bem-estar animal, manejo sanitário e boas práticas agropecuárias. Com intuito de atender as exigências da legislação brasileira e mundial, como também para oferecer produtos mais seguros aos consumidores, o Ministério da Agricultura, Pecuária e Abastecimento (MAPA) publicou a Instrução Normativa n. ${ }^{\circ}$ 77/2018, onde solicita a inclusão do Plano de Qualificação de Fornecedores de Leite (PQFL) no programa de autocontrole nos laticínios. Com este trabalho, objetivou-se propor a implementação do método PDCA, em conjunto a elaboração do PQFL, a fim de melhorar a qualidade do leite produzido em fazendas leiteiras da região serrana do estado do Espírito Santo, através dos indicadores de desempenho das boas práticas agropecuárias. Foi possível observar que o uso do ciclo PDCA integrada ao PQFL é uma possibilidade viável para propor melhorias contínuas nas atividades de produção leiteira, possibilitando solucionar problemas existentes, além de atender à legislação vigente.

Palavras-chave: boas práticas agropecuárias; controle de qualidade; laticínios; leite cru; segurança alimentar.

Abstract: Milk is a very complete food, source of proteins, lipids, vitamins, and minerals. In order to
obtain dairy products with good quality that contribute to the health and well-being of consumers, it is
needed a good quality raw material. For this, dairy farms need to improve agricultural management
through investment in genetics, nutrition, animal welfare, health management and good agricultural
practices. In order to meet the requirements of Brazilian and global legislation, as well as to offer safer
products to consumers, the Ministry of Agriculture, Livestock and Supply (MAPA) published the IN
n. 77/2018, which requests the inclusion of the Supplier Qualification Plan of Milk (PQFL) in the
dairy self-control program. This work aimed to analyze the effectiveness of the implementation of the
PDCA method (Plan, Do, Check and Act) in a dairy farm in the mountain region of the state of
Espírito Santo with the elaboration of the PQFL to improve the quality of the milk produced through 
the performance indicators of good agricultural practices. It was possible to observe that the use of the PDCA cycle integrated with the PQFL is a viable possibility to propose continuous improvements in milk production activities, making it possible to solve existing problems, in addition to complying with current legislation.

Keywords: dairy products; food safety; good agricultural practices; quality control; raw milk.

\section{INTRODUÇÃO}

Os consumidores estão cada vez mais exigentes em relação à qualidade dos alimentos ingeridos, graças à percepção do papel exercido pelos alimentos e seus componentes sobre a saúde. O leite é um alimento natural de grande valor nutricional com uma grande concentração de cálcio, que é essencial para a formação e manutenção dos ossos. As proteínas do leite apresentam propriedades funcionais, proporcionando a formação e manutenção dos tecidos. O leite contém vitamina $\mathrm{A}$, vitamina $\mathrm{B} 1, \mathrm{~B} 2$ e minerais que promovem o crescimento e mantêm uma vida saudável (CARVALHO, 2001).

O leite é uma das matérias-primas agrícolas mais importantes do planeta, incluindo um dos cinco produtos mais comercializados, tanto em volume como em valor. Aproximadamente mil milhões de pessoas no mundo dependem do leite para sobreviver e cerca de 600 milhões de pessoas vivem em 133 milhões de fazendas leiteiras em todo o mundo. Por conseguinte, cerca de $10 \%$ da população mundial depende diretamente da produção de leite (GDP, 2017). No ano de 2019, a produção de leite inspecionado no Brasil foi de 25,1 bilhões de litros de leite, na qual obteve um aumento de 2,3\% em volume em relação ao ano anterior (IBGE, 2020).

No Brasil, estima-se que a produção leiteira contribui com 5 milhões de empregos em 1,35 milhões de propriedades, sendo o segundo setor que mais emprega no país, gerando para o setor aproximadamente 100 bilhões por ano, sendo responsável por $76 \%$ do produto gerado pela pecuária nacional (GUIMARÃES, 2017). Segundo a FAO -
Food and Agriculture Organization of the Unites Nations, em 2017, o Brasil ocupou a quinta posição mundial no ranking de produção de litros de leite (FAO, 2018).

No entanto, a produção de leite continua a apresentar obstáculos na cadeia de produção, especialmente no que respeita às condições higiênico-sanitárias, que comprometem a qualidade final do produto (MACEDO; FREITAS, 2009).

As Instruções Normativas n. ${ }^{\circ} 76 \mathrm{e}$ n. ${ }^{\circ}$ 77, de 26 de novembro de 2018 do Ministério da Agricultura Pecuária e Abastecimento - MAPA entraram em vigor no mês de maio de 2019, nas quais foram definidos novos critérios para a produção de leite no país, especificando novos padrões de identidade e qualidade do leite cru refrigerado, do pasteurizado e do tipo A. Contagens de células bacterianas e somáticas são métodos de referência utilizados como indicadores da qualidade do leite cru. No art. $9^{\circ}$ da Instrução Normativa n. ${ }^{\circ} 77 / 2018$ estabelece que as indústrias devem implementar junto ao programa de autocontrole o plano de qualificação de fornecedores de leite com objetivo de melhorar a produtividade do sistema e a qualidade da matéria-prima da propriedade, tornando o produtor qualificado a fornecer leite aos laticínios (BRASIL, 2018a; BRASIL, 2018b).

O ciclo PDCA é uma metodologia que, primeiramente, faz um diagnóstico da situação atual e indica prioridades para melhorias. Com base nos dados encontrados, desenvolve-se um plano de ação em busca da resolução dos problemas e analisam-se os resultados obtidos para garantir a eficácia do trabalho. Caso o resultado esperado for atingido, padronizase para garantir a continuidade da melhoria 
(QUINQUIOLO, 2002; ANDRADE, 2003; CARVALHO; PALADINI, 2012).

O clico PDCA tem sido usado por muitas empresas na execução de seu planejamento estratégico, de forma eficiente e dinâmica, tendo como foco a melhoria contínua de processos de qualquer natureza (GOMES FILHO; GASPAROTTO, 2019). Essa metodologia tem sido aplicada no ambiente organizacional de vários segmentos do setor produtivo, desde empresas de grande porte do setor mineração e logística portuária (SILVA et al., 2017), a empresas produtoras e empacotadoras de alimentos (LONGO et al., 2016), e até mesmo pequenas empresas familiares (DIAS; ROTTA, 2019)

Levando em consideração a versatilidade e possibilidades de aplicação da ferramenta PDCA, objetivou-se com este trabalho utilizar este método na gestão da qualidade na cadeia produtiva do leite, por meio do uso do ciclo PDCA para auxiliar na elaboração e execução do plano de qualificação de fornecedores de leite (PQFL), a fim de melhorar a qualidade do leite produzido, através dos indicadores de desempenho das boas práticas agropecuárias em fazendas leiteiras da região serrana do estado do Espírito Santo.

\section{REFERENCIAL TEÓRICO}

\subsection{ASPECTOS DA QUALIDADE DO LEITE}

O leite é definido como o produto oriundo da ordenha completa e ininterrupta, em condições de higiene, de vacas sadias, bem alimentadas e descansadas (BRASIL, 2002). O leite, quanto ao seu aspecto e cor, é um líquido branco, opaco, duas vezes mais viscoso que água, com sabor e odor característicos, produzido de forma adequada, isento de substâncias estranhas (BRASIL 2018a).

O leite precisa apresentar requisitos de qualidade como a características físico- químicas, microbiológica e livres de contaminantes e conservantes, conforme estabelecido em legislação específica do Ministério da Agricultura, Pecuária e Abastecimento (BRASIL, 2017).

O MAPA estabelece parâmetros para medir a qualidade do leire cru, tais quais, características sensoriais como cor, odor e aspecto normais, características físico-químicas tais como gordura, proteína, lactose, sólidos não gordurosos, sólidos totais, acidez titulável, densidade, índice crioscópico. Não devem apresentar substâncias estranhas à composição do leite como agentes inibidores de crescimento microbiano, neutralizantes de acidez, reconstituintes de densidade e resíduos de uso veterinário. Análises microbiológicas são exigidas como indicadores de qualidade como a contagem de bactérias totais (CBT), que correspondem à quantidade de bactérias presentes no leite. Também é avaliada a contagem de células somáticas (CCS), que pode indicar a presença de mastite subclínica nas vacas em lactação (BRASIL, 2018a).

O grande desafio para melhorar a qualidade do leite não se limita apenas pelo conhecimento existente em si, mas também pela capacidade de transformar o conhecimento em prática (MORE, 2009). No entanto, a produção de leite continua a apresentar obstáculos na cadeia de produção, especialmente no que respeita às condições higiênico-sanitárias, que comprometem a qualidade final do produto (MACEDO; FREITAS, 2009).

\subsection{BOAS PRÁTICAS AGROPECUÁRIAS (BPA)}

As BPA podem ser vistas como uma forma de fazer avançar o papel multifuncional da agricultura, uma vez que as BPA são um sistema de atividades dos agricultores destinado a melhorar a sustentabilidade do ambiente, da economia e da sociedade (FAO, 2003). 
O guia de boas práticas agropecuárias de leite publicado pela FAO estabelece práticas chaves e contém uma série de recomendações que contribuem para a sua adoção. Compreende seis áreas principais: saúde animal, higiene na ordenha, alimentos e água, bem-estar animal, meio ambiente e gestão socioeconômica (FAO, 2013).

$\mathrm{O}$ PQFL tem como requisito as boas práticas agropecuárias, estruturado no planejamento, gestão, monitoramento, ações corretivas e auditorias de verificação no intuito de qualificar os fornecedores de leite de forma de melhoria contínua e evolutiva visando à qualidade e segurança do leite (MAPA, 2020).

\subsection{O CICLO PDCA}

O ciclo PDCA, também conhecido como ciclo de Shewhart, ciclo da qualidade ou ciclo de Deming, é um método de gestão de qualidade que tem como função a melhoria contínua, assistência no diagnóstico, análise e prognóstico de problemas organizacionais, sendo extremamente útil para a solução de problemas e tomada de decisão, capaz de indicar o caminho a ser seguido para que os objetivos estipulados no plano de ação possam ser alcançados com melhores resultados. $\mathrm{O}$ conceito do método de melhoria foi originalmente desenvolvido na década de 1930, nos laboratórios da Bell Laboratories nos Estados Unidos, pelo estatístico americano Walter A. Shewhart, como um ciclo de controle estatístico do processo, que pode ser continuamente repetido em qualquer processo ou problema (QUINQUIOLO, 2002; CARVALHO; PALADINI, 2012).

Shewhart propôs o ciclo PDCA, que direcionaria a análise e solução de problema, percorrendo o ciclo de planejar, fazer, checar o resultado e depois agir, ou seja, implementar a melhoria, com enfoque de melhoria contínua. Estes conceitos foram aprimorados posteriormente e difundidos em conjunto por Shewhart e W.
Edwards Deming. Deming, que exerceu influência nas bases estatísticas e no foco ao controle da qualidade, teve sua ótica guiada pelo pensamento de que o trabalhador tem papel fundamental na consolidação da boa gestão da qualidade empresarial, assim como, a alta gerência (CARVALHO; PALADINI, 2012).

É importante ressaltar que esse método vai além do pensamento estatístico, pois promove um alinhamento estratégico da qualidade, desdobrada em projetos prioritários. Além disso, existe forte ênfase na relação custo-benefício desse tipo de planejamento, cujos ganhos, em algumas empresas, são expressivos (CARVALHO; PALADINI, 2012).

O ciclo PDCA foi concebido para ser utilizado como um modelo dinâmico, que pode ser aplicado a uma variedade de configurações organizacionais, podendo ser dividido em quatro etapas bem definidas: Plan, Do, Check, Act (Figura 1). A conclusão de um ciclo terá início no ciclo seguinte, e assim por diante. Num espírito de melhoria contínua da qualidade, o processo pode sempre ser reanalisado e um novo processo de mudança pode ser iniciado (ANDRADE, 2003).

Figura 1: Modelo dinâmico do ciclo PDCA.
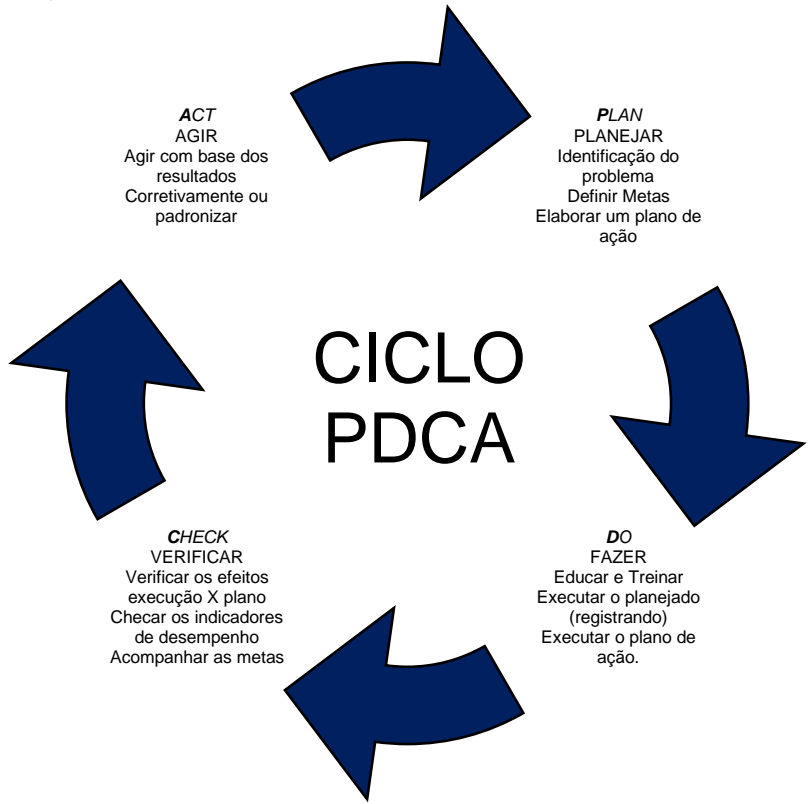

Fonte: Adaptado de CAMPO, 1992. 
A primeira fase, planejamento, é para identificar o problema, estabelecer o objetivo, analisar a situação, analisar o processo e a causa, e depois desenvolver o plano de ação $5 \mathrm{~W} 2 \mathrm{H}$. Este é o passo principal, pois é a partir do plano que as outras etapas serão baseadas (BADIRU, 1993). O 5W2H (W: What? O que?; Why? Por quê?; Where? Onde?; Who? Quem?; When? Quando?; How? Como?; How much? Quanto custa?) consiste em uma ferramenta prática capaz de organizar atividades, as responsabilidades e os prazos para a execução que precisam ser desenvolvidas pelas propriedades (OLIVEIRA, 1996). Em outras palavras, é preciso responder às sete perguntas básicas sobre a ação: que ação será executada?; Quem irá executar?; Onde será executada?; Quando será executada?; Por que será executada? Como será executada?; Quanto custará executar? (LENZI; KIESEL; ZUCCO, 2010).

O segundo passo é a execução, é basicamente a realização do plano de ação, obedecendo: o que fazer, quem fazer, onde, quando, por que, como e quando (5W2H). É também nesta fase que as pessoas são formadas para realizar operações e recolher dados (CAMARGO, 2011).

A terceira etapa é a verificação, que visa relacionar o que foi feito com o que foi planeado, a fim de validar os resultados. A eficácia do plano é também analisada. Quando não são encontrados problemas, é adaptada uma nova rotina. Se houver distorções de objetivos na fase de execução, tal é corrigido na fase seguinte do ciclo (BALLESTERO-ALVAREZ, 2010).

A última fase, de ação corretiva, pode ter dois objetivos: 1) a padronização do plano para se tornar a nova rotina, quando na fase anterior mostrou eficácia; e 2) quando na fase anterior houve não conformidades, serão aplicadas ações corretivas para evitar a recorrência de falhas (TUBINO, 2009).
No final de cada ciclo que tem um problema identificado e resolvido, é possível iniciar um novo ciclo. Cada ciclo completo aumenta o nível de qualidade da empresa, tornando o ciclo PDCA uma ferramenta de melhoria contínua. A rotação do ciclo PDCA deve ser constante para procurar sempre atingir as qualificações mais exigentes (TUBINO, 2009; CAMARGO, 2011).

O gerenciamento eficaz dos processos organizacionais gera resultados positivos, no sentido de aumentar a qualidade dos produtos e melhorar o desempenho organizacional. Assim, o conceito de melhoria contínua é aplicado tanto na busca de soluções para os problemas, quanto na melhoria sistemática e contínua, de modo a alcançar níveis mais elevados de qualidade e performance organizacional, utilizando o ciclo PDCA (CARVALHO; PALADINI, 2012).

A utilização do ciclo PDCA no ambiente organizacional é um caminho para melhorar os resultados e alavancar o desempenho das empresas, auxiliando no diagnóstico e no prognóstico de problemas (GOMES FILHO; GASPAROTTO, 2019).

\section{MATERIAIS E MÉTODOS}

A metodologia utilizada neste trabalho trata-se de uma abordagem qualitativa e descritiva. Este estudo foi realizado em uma agropecuária do ramo leiteiro, que possui uma usina de beneficiamento de leite (laticínio), situada no município de Santa Teresa, região serrana do estado do Espírito Santo. Foram escolhidas duas fazendas produtoras de leite, situadas nos municípios de Santa Teresa e Venda Nova do Imigrante, designadas de Fazendas A e B, respectivamente, as quais fornecem a matéria-prima para o laticínio da agropecuária.

A coleta de dados ocorreu no primeiro semestre de 2020, tendo como foco a realização de visitas técnicas nas 
fazendas, entrevistas aplicadas aos produtores e observações in loco.

Para a realização do diagnóstico das propriedades, foi utilizado uma lista de verificação de BPA, tomando por base a lista fornecida pelo MAPA na ocasião das auditorias às quais as fazendas foram submetidas, no intuito de elaboração do Plano de Qualificação de Fornecedores de Leite (PQFL), uma vez que a orientação do MAPA exige que os fornecedores alcancem os níveis "bom" e "excelente" (MAPA, 2020).

Para verificar o nível de controle na fazenda, foi adaptado o formulário de verificação com referência às boas práticas agropecuárias fornecidas pelo MAPA. Os itens a serem observados foram: I. gestão da propriedade; II. gestão de insumos; III. manejo sanitário; IV. manejo alimentar e armazenamento de alimentos; V. qualidade da água; VI. higiene pessoal e saúde dos trabalhadores; VII. controle integrado de pragas; VIII. capacitação dos trabalhadores; IX. manejo de ordenha e pós-ordenha; X. refrigeração e estocagem do leite; XI. manejo de resíduos e tratamento de dejetos e efluentes; XII. uso racional e estocagem de produtos químicos, agentes tóxicos e medicamentos veterinários; XIII. manutenção preventiva e calibragem de equipamentos; XIV. adoção de práticas de manejo racional e de bem-estar animal; XV. adequação das instalações, equipamentos e utensílios para produção de leite; XVI. controle de fornecedores de insumos agrícolas e pecuários (MAPA, 2019). Cada item foi avaliado como conforme (C) quando o item especificado foi atendido pela propriedade, não conforme (NC) quando o item não foi atendido ou não aplicável (NA) quando o item não influência na qualidade do leite e nas boas práticas agropecuárias.

Para a caracterização dos processos de produção, com base nas BPA, para cada um dos itens foi atribuído um peso/pontuação, de acordo com a criticidade (insignificante, baixo, moderado, elevado e crítico) e, os critérios utilizados para definição de não conformidades foram classificados a partir do quadro de risco. As fazendas foram categorizadas e classificadas, por perfil, obedecendo aos critérios estabelecidos no quatro de categorias (ruim, regular, bom e excelente) (Tabela 1).

Tabela 1: Categorização de acordo com o grau de conformidade e sistema de pontuação em relação à aplicação das boas práticas agropecuárias.

\begin{tabular}{lcc}
\hline Classificação & Pontuação & $\begin{array}{c}\text { Porcentagem de } \\
\text { conformidade } \\
\text { mínima }\end{array}$ \\
\hline RUIM & $0-192$ & $0 \%$ \\
REGULAR & $193-289$ & $50 \%$ \\
BOM & $290-386$ & $75 \%$ \\
EXCELENTE & 387 & $100 \%$ \\
\hline
\end{tabular}

Fonte: Os autores (2021).

Os resultados obtidos foram tabulados e procedidos às análises de interpretação, sendo as evidências de não conformidades destacadas para subsidiar a elaboração do PQFL, com o uso do Ciclo PCDA. Com o objetivo de atender as metas estabelecidas para os indicadores de gerenciamento anteriormente referidos adotou-se a metodologia PDCA proposta por Deming (1992) com adaptações, sendo composta das quatro etapas: planejar, executar, verificar e agir.

A primeira etapa, de planejamento, é fundamental uma análise do processo produtivo para identificação de problemas, buscar as causas para que a não conformidade aconteça e descrever as estratégias em um plano de ação para corrigir esses problemas.

A segunda etapa do ciclo é a implantação das melhorias e desenvolvimento de ações para executar as correções. Estudo financeiro para aquisições de meios de controle. Treinamento dos colaborados para execuções de forma correta das atividades. 
A terceira fase consiste em acompanhar a efetividade de implantação das ações, verificando-se o nível de adequação das alterações solicitadas.

O quarto e último grupo é a padronização ou adaptações necessárias para que a operação seja executada para alcançar a melhoria.

\section{RESULTADOS E DISCUSSÃO}

\subsection{PERFIL DA FAZENDA}

O perfil comparativo da produção de leite das fazendas analisadas está apresentado na Tabela 2.

A Fazenda A, localizada no município de Santa Teresa/ES, possui 690 vacas leiteiras das raças Girolando, Holandesa e Jersey, tendo em média de 250 animais em lactação, com produção média de $30 \mathrm{~kg}$ de leite/vaca/dia, totalizando uma média de $7.500 \mathrm{~kg}$ de leite/dia, obtidos através de três ordenhas diárias. A fazenda possui ordenhadeira mecânica tipo espinha de peixe, para a ordenha simultânea de 8 vacas, sendo o leite canalizado e armazenado em tanque de refrigeração, situado ao lado da usina de beneficiamento do laticínio.

A Fazenda B, localizada no município de Venda Nova do Imigrante/ES, possui 500 vacas leiteiras, da raça Girolanda, com 170 animais em lactação, com média de produção diária por vaca de $30 \mathrm{~kg}$ de leite/vaca/dia, perfazendo um total médio de $5.000 \mathrm{~kg}$ de leite/dia. A obtenção de leite é feita através de duas ordenhas diárias, com a utilização de ordenhadeira mecânica tipo espinha de peixe, para entrada de 8 animais em ordenha simultânea, com canalização do leite para um tanque de refrigeração, onde o leite permanece até ser transportado em caminhão com tanque isotérmico em aço inoxidável para a usina de beneficiamento, que fica distante $121 \mathrm{~km}$ da fazenda. O rebanho da Fazenda B possui genótipo A2A2, para a produção de beta caseína, sendo o leite destinado à fabricação de produtos com selo A2A2, que possuem apenas caseína A2, o que os confere uma digestão mais fácil por parte dos consumidores que não tem têm intolerância à lactose, mas, sentem algum desconforto após consumir produtos lácteos.

As duas fazendas atenderam os parâmetros microbiológicos do leite de acordo com a legislação vigente, onde o limite máximo para CCS é de até 500.000 $\mathrm{CS} / \mathrm{mL}$ e de CBT de no máximo 300.000 UFC/mL (BRASIL, 2018a). Elevadas CCS em leite provocam perdas no rendimento na produção de produtos lácteos, principalmente queijos, e a manutenção de baixas CCS indica boa saúde da glândula mamária dos animais do rebanho (SCHUKKEN et al., 1990). CBT é um parâmetro importante no ponto de vista de qualidade e higiene do leite, níveis altos prejudicam a produção e a vida útil de diversos produtos de leite e derivados (FONSECA; CARVALHO, 2004). Baixas contagens de bactérias totais são possíveis através de boas práticas agropecuárias, higienização de utensílios e equipamentos (equipamento de ordenha, tanque de expansão, caminhão etc.) que entram em contato, higienização e secagem dos tetos antes da ordenha e refrigeração do leite (MURPHY et al., 2016).

A produção de leite em quantidade e qualidade nutricional depende majoritariamente do aporte adequado de uma dieta rica, balanceada e do bem-estar animal (MÜHLBACH, 2003). Altos valores de gordura, proteína e sólidos totais é benéfico para as fábricas de laticínios devido à importância nutricional e econômica, obtendo melhores rendimentos na produção de queijos e aumento da estabilidade térmica do leite (SILVA et al., 1999).

O diagnóstico das propriedades, com relação à caracterização dos processos de produção, com base na conformidade de atendimento à BPA das Fazendas A e B, estão apresentados na Tabela 3. 
Tabela 2: Perfil de produção leiteira das fazendas fornecedoras de leite analisadas.

\begin{tabular}{|c|c|c|}
\hline Característica & Fazenda $\mathrm{A}$ & Fazenda B \\
\hline Raça dos animais & $\begin{array}{l}\text { Girolando, } \\
\text { Holandesa e } \\
\text { Jersey }\end{array}$ & $\begin{array}{l}\text { Girolando } \\
\text { A2A2 }\end{array}$ \\
\hline $\mathrm{N}^{\circ}$ total de animais & 690 & 500 \\
\hline $\begin{array}{l}\mathrm{N}^{\mathbf{o}} \text { de animais em } \\
\text { lactação }\end{array}$ & 250 & 170 \\
\hline $\mathrm{N}^{\mathrm{o}}$ de ordenhas diárias & 3 & 2 \\
\hline $\begin{array}{l}\text { Média de produção } \\
\text { leite/vaca/dia (kg) }\end{array}$ & 30 & 30 \\
\hline $\begin{array}{l}\text { Média de produção } \\
\text { diária de leite (kg) }\end{array}$ & 7.500 & 5.000 \\
\hline $\begin{array}{l}\text { Média geométrica de } \\
\operatorname{CCS}^{*}(\text { x mil CS/mL) }\end{array}$ & 244 & 234 \\
\hline $\begin{array}{l}\text { Média geométrica de } \\
\text { CBT* }^{*} \text { (x mil } \\
\text { UFC/mL) }\end{array}$ & 6 & 10 \\
\hline Média de GOR* $(\%)$ & 3,92 & 3,92 \\
\hline Média de PRO* $(\%)$ & 3,32 & 3,34 \\
\hline Média de $\operatorname{EST}^{*}(\%)$ & 12,79 & 12,92 \\
\hline
\end{tabular}

Baseado nos conceitos da Tabela 1, as duas fazendas foram classificadas como bom, onde a fazenda A obteve 357 pontos e a fazenda B, 368 pontos, sobre a aplicação do diagnóstico sobre as BPA (Tabela 3). Resultado indica o alto nível de adoção das boas práticas agropecuárias nas fazendas leiteiras.

\subsection{PLANEJAMENTO (Plan)}

\subsubsection{Identificação do problema}

O diagnóstico proposto foi aplicado e avaliado cada requisito. Os parâmetros sobre a gestão da propriedade, gestão de insumos, manejo sanitário, higiene pessoal e saúde dos trabalhadores, controle integrado de pragas, manejo de ordenha e pós-ordenha, refrigeração e estocagem do leite, manejo de resíduos e tratamento de dejetos e efluentes encontrou-se dentro dos padrões, desta forma as duas fazendas atenderam estes requisitos.

A fazenda A apresentou irregularidades como ausência de registros de aplicação de produtos químicos nas pastagens. Não foram constatados também os registros de treinamentos para os colaboradores, sobre as boas práticas agropecuárias e sobre o uso de agroquímicos e produtos de uso veterinário. Embora tenha uma empresa que realiza as manutenções dos equipamentos de ordenha, não há registros de manutenções executadas nos equipamentos. Apesar de apresentar instalações e técnicas de manejo que garantem o bem-estar animal, não foi encontrado registro de treinamentos sobre o manejo racional visando o bem-estar animal para os colaboradores.

A fazenda B apresentou condições desfavoráveis para a qualidade da água, não existindo registro de higienização dos reservatórios de água, além de não possuir tratamento da água. Contatou-se que não havia registros de aplicação de produtos químicos nas pastagens e forragens $\mathrm{e}$ aplicação de agroquímicos. Apesar de adotar técnicas e instalações adequadas que garantem o bem-estar animal, verificou-se que não havia registros de treinamentos dos colaboradores quanto ao bem-estar animal.

\subsubsection{Análise das causas}

As ausências de registros são justificadas por falta de conhecimento e cobrança por via dos administradores e de fiscalizações que não exigem a implantação dos registros.

\subsubsection{Plano de ação}

Frente às informações coletadas, foi utilizada para a elaboração do plano de ação a técnica $5 \mathrm{~W} 2 \mathrm{H}$, tendo como base a pontuação obtida em relação à aplicação das boas práticas agropecuárias (Tabela 3 ).

Os planos de ação foram elaborados e discutidos com os proprietários e gestores das fazendas para definir as ações, 
os prazos para as execuções e os colaboradores responsáveis pela execução do plano. Os planos de ação focaram na identificação das não conformidades do sistema de produção de cada fazenda e nas melhorias nos programas de treinamento dos funcionários.

Os funcionários devem passar por treinamentos sobre a importância da produção, controle e redução das não conformidades, mas para isso ocorrer, devem ser implementadas ferramentas de melhoria contínua

(COSTA;

GASPAROTTO, 2015).

O uso do ciclo PDCA de forma integrada para a melhoria contínua da qualidade, por meio da elaboração de planos de ação, visa aumentar o rendimento das empresas, contribuindo notadamente na melhoria da organização (GOMES FILHO; GASPAROTTO, 2019).

Tabela 3: Perfil de conformidade e pontuação obtida em relação à aplicação das boas práticas agropecuárias nas Fazendas A e B.

\begin{tabular}{|c|c|c|c|c|c|c|c|}
\hline \multirow[b]{2}{*}{ PARÂMETROS } & \multicolumn{3}{|c|}{ Fazenda A } & \multicolumn{3}{|c|}{ Fazenda B } & \multirow[b]{2}{*}{ Máx. } \\
\hline & $\begin{array}{c}\text { Não } \\
\text { Conforme }\end{array}$ & Conforme & Pontuação & $\begin{array}{c}\text { Não } \\
\text { Conforme }\end{array}$ & Conforme & Pontuação & \\
\hline Gestão da propriedade & $0 \%$ & $100 \%$ & 58 & $0 \%$ & $100 \%$ & 60 & 60 \\
\hline Gestão de insumos & $0 \%$ & $100 \%$ & 10 & $0 \%$ & $100 \%$ & 10 & 10 \\
\hline Manejo sanitário & $0 \%$ & $100 \%$ & 44 & $0 \%$ & $100 \%$ & 44 & 44 \\
\hline $\begin{array}{l}\text { Manejo alimentar e } \\
\text { armazenamento de alimentos }\end{array}$ & $7 \%$ & $93 \%$ & 51 & $7 \%$ & $93 \%$ & 51 & 55 \\
\hline Qualidade da água & $0 \%$ & $100 \%$ & 27 & $33 \%$ & $67 \%$ & 19 & 27 \\
\hline $\begin{array}{l}\text { Higiene pessoal e saúde dos } \\
\text { trabalhadores }\end{array}$ & $0 \%$ & $100 \%$ & 9 & $0 \%$ & $100 \%$ & 9 & 9 \\
\hline Controle integrado de pragas & $0 \%$ & $100 \%$ & 5 & $0 \%$ & $100 \%$ & 5 & 5 \\
\hline $\begin{array}{l}\text { Capacitação dos } \\
\text { trabalhadores }\end{array}$ & $100 \%$ & $0 \%$ & 0 & $0 \%$ & $100 \%$ & 9 & 9 \\
\hline $\begin{array}{l}\text { Manejo de ordenha e pós- } \\
\text { ordenha }\end{array}$ & $0 \%$ & $100 \%$ & 65 & $0 \%$ & $100 \%$ & 65 & 65 \\
\hline $\begin{array}{l}\text { Refrigeração e estocagem do } \\
\text { leite }\end{array}$ & $0 \%$ & $100 \%$ & 36 & $0 \%$ & $100 \%$ & 36 & 65 \\
\hline $\begin{array}{l}\text { Manejo de resíduos e } \\
\text { tratamento de dejetos e } \\
\text { efluentes }\end{array}$ & $0 \%$ & $100 \%$ & 14 & $0 \%$ & $100 \%$ & 14 & 14 \\
\hline $\begin{array}{l}\text { Uso racional e estocagem de } \\
\text { produtos químicos, agentes } \\
\text { tóxicos e medicamentos } \\
\text { veterinários }\end{array}$ & $29 \%$ & $71 \%$ & 24 & $14 \%$ & $86 \%$ & 29 & 33 \\
\hline $\begin{array}{l}\text { Manutenção preventiva e } \\
\text { calibragem de equipamentos }\end{array}$ & $50 \%$ & $50 \%$ & 5 & $0 \%$ & $100 \%$ & 8 & 8 \\
\hline $\begin{array}{l}\text { Adoção de práticas de } \\
\text { manejo racional e de bem- } \\
\text { estar animal }\end{array}$ & $33 \%$ & $67 \%$ & 9 & $33 \%$ & $67 \%$ & 9 & 12 \\
\hline Total de Pontos & & & 357 & & & 368 & 387 \\
\hline
\end{tabular}

Fonte: Os autores (2021). 


\subsection{EXECUTAR $(D o)$}

\subsubsection{Preparar a execução}

Para atingir as metas, os proprietários receberam os planos de ação para acompanharem as execuções. Entrou-se em contato com uma assistência técnica prestadora de serviço para auxiliar em alguns treinamentos.

\subsubsection{Treinar os envolvidos}

Os treinamentos foram realizados com os colaboradores envolvidos de acordo com cada função desempenhada, a fim de capacitá-los para a execução das operações de maneira correta e com a qualidade necessária.

\subsubsection{Executar as ações}

Os treinamentos realizados foram sobre boas práticas agropecuárias, manejo e bem-estar animal. Todos os colaboradores das fazendas A e B presentes assinaram uma lista de presença e receberam certificado de participação. Para Ribeiro et al. (2006), o manejo bem realizado, com higiene, possibilita ao produtor diminuir o risco de mastite do rebanho. Por outro lado, o manejo aversivo prejudica o bem-estar animal e reduz a produção de leite (PETERS et al., 2010).

Foram desenvolvidas planilhas para os registros de aplicação de produtos químicos, de uso veterinário e de manutenção, onde todos os colaboradores responsáveis foram orientados a preencher e assinar ao final na fazenda A. O uso inadequado de produtos químicos $\mathrm{e}$ produtos veterinários podem causar riscos e agravos à saúde do animal e humana (VRAGOVIĆ; BAŽULIĆ; NJARI, 2011).

$\mathrm{Na}$ fazenda $\mathrm{B}$ foi programada uma data para a higienização da caixa d'água e a instalação de um dosador de cloro para o tratamento da água. A utilização do cloro para o tratamento da água tem por objetivo a desinfecção da água, ou seja, a destruição de microrganismos patogênicos (BAZZOLI, 1993). Nas fazendas a má qualidade da água pode trazer prejuízos para a qualidade do leite. A contaminação do leite pode ocorrer por meio da água utilizada para enxágue de equipamentos, tanque de estocagem, ordenhadeira e utensílios (PICININ, 2010). Segundo Etcheverry (1997) a baixa qualidade microbiológica da água pode elevar a contagem de bactérias totais (CBT) e pode ser veículo de agentes causadores de mastite (PERKINS et al., 2009).

\subsection{VERIFICAR (Check)}

Ao final do prazo estabelecido no plano de ação das fazendas, foi realizada uma auditoria para verificar se as ações corretivas foram realizadas.

Verificou-se através da visita in loco que na fazenda $\mathrm{A}$, todos os itens propostos no plano de ação foram realizados dentro do prazo. Os registros estavam sendo realizados de acordo com as frequências de serviço.

$\mathrm{Na}$ fazenda $\mathrm{B}$ apenas o item relacionado à qualidade da água não foi realizado, pois não foi instalada uma bomba dosadora de cloro para o tratamento da água. $\mathrm{O}$ proprietário justificou a dificuldade em instalar o dosador de cloro no local, pois a água captada na fazenda é distribuída para o vilarejo e, portanto, gastaria muito para a manutenção da dosagem do cloro. Foi relatado que melhorias seriam propostas a fim de executar a não conformidade apresentada.

\subsection{AGIR (Act)}

No intuito de implementar a melhoria na qualidade do leite das fazendas fornecedoras, foram agendadas auditorias para acompanhar a efetividade das ações, no intuito de acompanhar a execução do plano de ação dos ajustes, adequações necessárias no mesmo e o planejamento contínuo de novas ações.

\section{CONCLUSÕES}

Neste estudo, foi possível observar que o uso do ciclo PDCA como um método de qualidade integrada ao PQFL é 
uma possibilidade viável para implementar melhorias contínuas na qualidade do leite, possibilitando solucionar problemas existentes e a correção de não conformidades, além de atender à legislação vigente, por parte dos fornecedores

O uso do ciclo PDCA auxiliou na elaboração de planos de ação focados nas boas práticas agropecuárias, visando a promoção de bons resultados para as empresas do ramo de produção leiteira.

\section{AGRADECIMENTOS}

Agradecimento às Agropecuária e as fazendas participantes deste estudo e ao curso de Pós-Graduação em Controle de Qualidade e Segurança de Alimentos do Instituto Federal do Espírito Santo - Ifes Campus Piúma.

\section{REFERÊNCIAS}

ANDRADE, F. F. O método de melhorias PDCA. 2003. Dissertação de Mestrado (Engenharia de Construção Civil e Urbana) - Escola Politécnica, Universidade de São Paulo. São Paulo, 2003.

BADIRU, A. B.; AYENI, B. J.

Practitioner's guide to quality and process improvement. London: Chapman \& Hall, 353p., 1993.

BALLESTERO-ALVAREZ, M. E. Gestão da qualidade, produção e operações. São Paulo: Atlas, 2010.

\section{BAZZOLI, N. O uso da desinfecção no combate à cólera. Apostila da Fundação Nacional de Saúde - Coordenação Regional de Minas Gerais. Recife: FNS/Opas (Mimeo.), 1993.}

BRASIL. Ministério da Agricultura Pecuária e Abastecimento. Decreto n. ${ }^{\circ}$ 9.013, de 29 de março de 2017.

Regulamenta a Lei n. ${ }^{\circ} 1.283$, de 18 de dezembro de 1950 , e a Lei n. ${ }^{\circ} 7.889$, de 23 de novembro de 1989, que dispõem sobre a inspeção industrial e sanitária de produtos de origem animal. Diário Oficial da União, Brasília, DF, 30 mar. de 2017. Seção 1, p. 3. 2017.

BRASIL. Ministério da Agricultura Pecuária e Abastecimento. Instrução Normativa . $^{\circ} 51$ de 18 de setembro de 2002. Regulamento Técnico de Produção, Identidade e Qualidade de Leite Tipo A, Tipo B, Tipo C e Cru refrigerado. Diário Oficial da União, Brasília, DF, 29 set. de 2002. Seção 1, p. 13, 2002.

BRASIL. Ministério da Agricultura Pecuária e Abastecimento. Instrução Normativa n. ${ }^{\circ} 76$ de 26 de novembro de 2018. Regulamenta a identidade e as características de qualidade que devem apresentar o leite cru refrigerado, o leite pasteurizado e o leite pasteurizado tipo A.

Diário Oficial da União, Brasília, DF, 30 nov. de 2018. Seção 1, p. 9. 2018a.

BRASIL. Ministério da Agricultura Pecuária e Abastecimento. Instrução Normativa n. ${ }^{\circ} 77$ de 26 de novembro de 2018. Define os critérios e procedimentos para a produção, acondicionamento, conservação, transporte, seleção e recepção do leite cru em estabelecimentos registrados no serviço de inspeção oficial. Diário Oficial da União, Brasília, DF, 30 nov. de 2018. Seção 1, p. 10. 2018 b.

CAMARGO, W. Controle de Qualidade Total. Curitiba: Instituto Federal do Paraná, 2011.

CAMPOS, V. F. TQC: Controle da Qualidade Total (no estilo japonês). Belo Horizonte: Fundação Christiano Ottoni, 1992.

CARVALHO, L. A. et al. Sistema de produção de leite (Cerrado). Embrapa Gado de Leite, Goiânia: 2001. Disponível em: 
$<$ https://sistemasdeproducao.cnptia.embrap a.br/FontesHTML/Leite/LeiteCerrado/intro ducao.html>. Acesso em: 10 maio 2020.

CARVALHO, M. M; PALADINI, E. P. Gestão da Qualidade: Teoria e casos. $2^{a}$ edição. Rio de Janeiro: Elsevier, 2012.

COSTA, A. P.; GASPAROTTO, A. M. S. Um estudo sobre o ciclo PDCA como ferramenta auxiliar para o controle de produtos não conformes. In: III SIMTEC Simpósio de Tecnologia da FATEC Taquaritinga, 2015. Anais... Taquaritinga: FATEC, 2015.

DEMING, W. E. Qualidade: A Revolução da Administração. São Paulo: Editora Saraiva, 1992.

DIAS, G. S.; ROTTA, I. S. Aplicação do método PDCA de melhorias em uma pequena empresa familiar de embalagens. In: IX Congresso Brasileiro de Engenharia de Produção, 2019, Ponto Grossa. Anais... Ponta Gross: Abepro, 2019.

ETCHEVERRY, J. C. R. Incidencia de la calidad del agua en la calidad de la leche.

Anais Seminario Regional de Calidad de Leche, Buenos Aires, p.163-170, 1997.

FAO. Development of a Framework for Good Agricultural Practices. Committee on Agriculture. Seventeenth session. Roma: FAO, 2003. Disponível em: <http://www.fao.org/docrep/meeting/006/y 8704e.htm>. Acesso em: 01 maio 2020.

FAO. Dairy Market Review. Roma: FAO, 2018. Disponível em: <http://www.fao.org/3/I9210EN/i9210en.p df>. Acesso em: 03 de mar. 2020.

FAO. Guia de boas práticas na pecuária de leite. 2013. Produção e saúde animal. Roma: FAO/IDF, 2013.

FONSECA, F. L.; CARVALHO, M. P. O grande gargalo: tecnologia, preço e qualidade do leite. In: FONSECA, F. L.; CARVALHO, M. P. Leite, política e derivados. São Paulo: Quiron Livros, p. 23-30, 2004.

GDP - Global Dairy Platform. Annual Review 2016. Rosemont, IL, 2017. Disponível em: <https://www.globaldairyplatform.com/wp -content/uploads/2018/04/2016-annualreview-final.pdf $>$. Acesso em: 22 out. 2020.

GOMES FILHO, V.; GASPAROTTO, A. M. S. A importância do ciclo PDCA aplicado à produtividade da indústria no brasil. Revista Interface Tecnológica, v. 16, n. 2, p. 383-392, 2019.

GUIMARÃES, A. J. S. Avaliação da qualidade do leite cru refrigerado em relação ao enquadramento legal e o efeito da sazonalidade sobre o preço pago aos produtores. Dissertação (Mestrado em Gestão Organizacional) Universidade Federal de Goiás - Catalão, 2017.

IBGE. Pesquisa trimestral de leite. Brasília, DF, 2020. Disponível em: <https://sidra.ibge.gov.br/home/leite/brasil >. Acesso em: 20 out. 2020.

LENZI, F. C.; KIESEL, M. D.; ZUCCO, F. D. Ação empreendedora: como desenvolver e administrar o seu negócio com excelência. São Paulo: Editora Gente, 2010 .

LONGO, M. T.; MORAES, K. K.; BARBOSA, P. P.; SANTOS, V. C.; RODRIGUES, G. J. Aplicação do ciclo PDCA e de ferramentas da qualidade em uma empresa produtora e empacotadora de alimentos. In: XXXVI Encontro Nacional de Engenharia de Produção - Contribuições da Engenharia de Produção para Melhores Práticas de Gestão e Modernização do Brasil, 2016, João Pessoa. Anais... João Pessoa: Abepro, 2016. 
MACEDO, L. C. S.; FREITAS, J. A.

Ocorrência de resíduos de antimicrobianos em leite. Revista de Ciências Agrárias, v. 52, p. 147-57, 2009.

MAPA - Ministério da Agricultura e Pecuária e Abastecimento. Guia orientativo para elaboração do plano de qualificação de fornecedores de leite (PQFL). Brasília, v. 7. 2020. Disponível em: <https://www.gov.br/agricultura/ptbr/assuntos/producaoanimal/arquivos/PQFL01Guiaparaelaborao v.17b.pdf>. Acesso em: 26 dez. 2020.

MAPA - Ministério da Agricultura e Pecuária e Abastecimento. Lista de verificação de BPA. v. 8, 2019.

Disponível em: $<$ https://www.gov.br/agricultura/ptbr/assuntos/producao-animal/plano-dequalificacao-de-fornecedores-de-leite> . Acesso em: 26 dez. 2020.

MORE, S. Global trends in milk quality: implications for the Irish dairy industry.

Irish Veterinary Journal, v. 62, Suppl.4, p. 5-14, 2009.

MÜHLBACH, P. R. F. Nutrição da vaca em lactação e a qualidade do leite. In: Simpósio de Bovinocultura de Leite, 2003, Chapecó. Anais... Chapecó: Sociedade Catarinense de Medicina Veterinária, 2003.

MURPHY, S. C. et al. Influence of raw milk quality on processed dairy products: How do raw milk quality test results relate to product quality and yield?. Journal of Dairy Science, Champaign, v. 99, n. 12, p. 10128-10128, 2016.

OLIVEIRA, S. T. Ferramentas para o aprimoramento da qualidade. 2. ed. São Paulo: Editora Pioneira, 119 p., 1996.

PERKINS, N. et al. An analysis of the relationship between bulk tank milk quality and wash water quality on dairy farms in Ontario, Canada. Journal Dairy Sciense. v. 92, n. 8, p. 3714-3722, 2009.

PETERS, M. D. P. et al. Manejo aversivo em bovinos leiteiro e efeitos no bem-estar, comportamento e aspectos produtivos. Archivos de Zootecnia, Córdoba, v. 59, p. 435-442, 2010.

PICININ, L. C. A. Quantidade e qualidade da água na produção de bovinos de leite. In: Simpósio de Produção Animal e Recursos Hídricos, Embrapa Suínos e Aves: 2010, Concórdia, SC. Anais... Concordia, p. 57-71, 2010.

QUINQUIOLO, J. M. Avaliação da Eficácia de um Sistema de Gerenciamento para Melhorias Implantado na Área de Carroceria de uma Linha de Produção Automotiva. TaubatéSP: Universidade de Taubaté, 2002.

RIBEIRO, M. E. R.; ZANELA, M. B.; MARTINS, P. R. G. Mastite. In: PEGORARO, L. M. C (Org.). Noções sobre produção de leite. Pelotas: Embrapa Clima Temperado, p. 119- 132, 2006.

SILVA, C. O.; AGOSTINO. I. R. S.; SOUSA, S. R. O.; FROTA, P. C.; OLIVEIRA, R. D. A utilização do método PDCA para melhoria dos processos: um estudo de caso no carregamento de navios. Revista ESPACIOS, v. 38. n. 27, p. 9-22, 2017.

SILVA, P. H. F.; PORTUGAL, J. A. B.; CASTRO, M. C. D.. Qualidade e Competitividade em Laticínios. Juiz de Fora: EPAMIG - Centro Tecnológico ILCE, 116 p., 1999.

SCHUKKEN, Y. H. et al. Our industry today: population Dynamics of bulk milk somatic cell counts. Journal of Dairy Science, v. 73, n. 5, p. 1343-1350, 1990. 
TUBINO, D. F. Planejamento e Controle da Produção: teoria e prática. $2^{\mathrm{a}}$ ed. São Paulo: Atlas, 2009.

VRAGOVIĆ, N.; BAŽULIĆ, D.; NJARI, B. Risk assessment of streptomycin and tetracycline residues in meat and milk on Croatian market. Food and Chemical Toxicology, Oxford, v. 49, n. 2, p. 352355, 2011. 